\title{
Aspectos legais da pesca artesanal do camarão sete-barbas no município de Penha, SC: o papel do defeso
}

\author{
Legal aspects of seabob-shrimp artisanal fisheries in the city of Penha, SC: the \\ role of the closed season
}

\section{Aspectos legales de la pesca artesanal del camarón siete barbas em la ciudad de Penha, SC: el papel del cierre}

\author{
Aspects juridiques de la pêche artisanale de la crevette Xiphopenaeus kroyeri \\ dans la Ville de Penha, Santa Catarina, Brésil: le rôle de la période de fermeturea
}

\author{
Renata Costella Acauan ${ }^{1}$ \\ Benjamim Teixeira ${ }^{1}$ \\ Marcus Polette ${ }^{2}$ \\ Joaquim Olinto Branco²
}

Recebido em 12/04/2017; revisado e aprovado em 25/07/2017; aceito em 14/11/2017

DOI: http://dx.doi.org/10.20435/inter.v19i3.1581

\begin{abstract}
Resumo: Buscando contribuir para a gestão da pesca artesanal, foram avaliados os aspectos legais da atividade no município de Penha, SC, com destaque ao defeso do camarão sete-barbas (Xiphopenaeus kroyeri). Identificaram-se 36 normas que regulamentam a atividade, muitas das quais são ineficazes. A alteração do defeso é a principal reivindicação dos pescadores; constatou-se ainda que a maioria dos trabalhadores que recebem o seguro-defeso não teriam direito ao benefício, pois atuam na preparação do pescado.
\end{abstract}

Palavras-chave: gestão pesqueira; defeso; legislação pesqueira.

Abstract: Aiming to contribute to the management of artisanal fisheries, the legal aspects of the activity in the city of Penha, SC, were evaluated, with emphasis on the seabob-shrimp (Xiphopenaeus kroyeri). A total of 36 standards that regulate this activity were identified, many of which are ineffective. Changing the closed season is the main claim of fishermen; it was also observed that the majority of the workers who receive the insurance are not entitled to the benefit as they are involved in the preparation of the fish.

Keywords: fishery management; closed season; fisheries legislation.

Résumé: Pour contribuer à la gestion de la pêche artisanale de la crevette Xiphopenaeus kroyeri, les aspects juridiques de l'activité dans la Ville de Penha ont été évalués. Au tout, 36 normes règlent cette pêche, beaucoup d'entre elles inefficaces ou problématiques comme la période de fermeture. Le changement de cette période est la principale revendication des pêcheurs. En outre, il fut possible d'observer que la plupart des travailleurs n'auraient pas le droit de toucher l'assurance-chômage, car ils travaillent au traitement du poisson.

Mots-clés: gestion de la pêche; période de fermeture; aspects juridiques.

Resumen: Buscando contribuir a la gestión de la pesca, se evaluaron los aspectos jurídicos de la actividad en el municipio de Penha, SC, destacando el cierre del camarón siete barbas (Xiphopenaeus kroyeri). Se identificó 36 normas que regulan la actividad, muchas de las cuales son ineficaces. Cambio de la temporada del cierre es la principal demanda de los pescadores; se observó, aunque la mayoría de los trabajadores que reciben el seguro de cierre no tendría derecho a la prestación, ya que actúan en la preparación de pescado. Palabras clave: gestión de la pesca; cierre; legislación pesquera.

\section{INTRODUÇÃO}

A produção pesqueira mundial (extrativista e aquicultura), em 2014, alcançou 167,2 milhões de toneladas, sendo 87,5\% utilizados na alimentação humana, com uma oferta per capita de 20

\footnotetext{
$\overline{{ }^{1} \text { Instituto Federal }}$ de Educação, Ciência e Tecnologia de Santa Catarina (IFSC), Florianópolis, Santa Catarina, Brasil.

${ }^{2}$ Universidade do Vale do Itajaí (Univali), Itajaí, Santa Catarina, Brasil.
} 
kg ao ano, o que corresponde a $17 \%$ da proteína animal e sustento para 10 a $12 \%$ da população mundial (FOOD AND AGRICULTURE ORGANIZATION OF THE UNITED NATIONS [FAO], 2016). Desde 1990, o setor vem incrementando a demanda de emprego, contribuindo em 2014 com aproximadamente 56,6 milhões de postos distribuídos entre Ásia (84\%), África (10\%), América Latina e Caribe (4\%) (FAO, 2016).

A pesca extrativa em 2014 contribuiu com 55,9\% da produção mundial de pescados (93,4 milhões de toneladas), sendo $87,2 \%$ desse montante oriundo da pesca marinha e costeira (FAO, 2016). No Brasil, essa modalidade pesqueira representava aproximadamente 760 mil toneladas (BRASIL, 2015a; FAO, 2016). O estado de Santa Catarina destaca-se como principal produtor nacional de pescados (BRASIL, 2011; UNIVALI, 2013), onde a pesca, maricultura e turismo desempenham papel relevante na economia das comunidades litorâneas, apesar de serem atividades conflitantes e provocarem a disputa pelo espaço costeiro (VIANNA; BONETTI; POLETTE, 2012; BAIL; BRANCO, 2007).

O camarão sete-barbas Xiphopenaeus kroyeri (Heller, 1862) é um recurso de grande importância mundial, sendo a pesca por meio de redes de arrasto com portas a arte comercial mais utilizada na captura desta espécie (GILLETT, 2008). Considerada uma espécie sobre-explotada nas regiões Sudeste e Sul do Brasil (VASCONCELLOS; DIEGUES; SALES, 2007), o camarão sete-barbas é o principal recurso econômico da pesca artesanal na Armação do Itapocoroy, município de Penha, SC, que conta com uma média de 75 embarcações em atividade (BRANCO, 2005).

Os problemas na pesca e aquicultura dos países em desenvolvimento, geralmente estão associados à falta de organização e estrutura, ausência de dados dos recursos explotados, políticas e gestão inadequadas (ELER; MILLANI, 2007; FAO, 2013), em que a complexidade dos elementos, associada às relações de causa e efeito, geralmente disponibilizam alguma ordem nas estruturas desse complicado sistema (MULLER; BURKHARD, 2012). No Brasil, várias ações procuram assegurar a sustentabilidade do setor, como um rígido controle dos aparelhos e permissões de pesca, período de defeso, limite do tamanho dos exemplares capturados, criação de reservas marinhas, mecanismos de escape da fauna acompanhante (FRANCO et al., 2009).

Na pesca de arrasto, o defeso, definido pela Lei 11.959 de 2009 como "a paralisação temporária da pesca para a preservação da espécie, tendo como motivação a reprodução e/ou recrutamento [...]", além de trazer benefícios econômicos - com a recuperação dos estoques, gerando ganhos pelo incremento em peso da captura, também gera benefícios ecológicos- com a recuperação do habitat e da biodiversidade, bastante afetados pelas redes de arrasto (SANTOS; BRANCO; BARBIERI, 2013).

Medidas como o defeso, acompanhadas da limitação no tamanho dos petrechos de pesca, mostram-se promissoras na gestão da pesca artesanal de camarões e alguns peixes marinhos, mas sua efetividade depende de uma série de fatores, como a participação dos pescadores artesanais, numa cogestão participativa dessas políticas para o sucesso do ordenamento pesqueiro (DIEGUES, 2001; VASQUES; COUTO, 2011).

Procurando assegurar a renda do pescador artesanal durante o defeso, foi instituído no Brasil o seguro-defeso, que permite ao pescador receber um auxílio financeiro em períodos de restrições da pesca. Para acessar esse benefício, é necessário comprovar o exercício profissional artesanal ininterrupto (Lei n. 10.779 de 2003; Decreto n. 8.424 de 2015; Lei n. 13.134 de 2015). Essa comprovação, geralmente, está envolta num cenário de descaso e ilegalidade da atividade pesqueira. 
Dessa forma, este trabalho teve como objetivo avaliar os aspectos legais da pesca artesanal no município de Penha, SC, com ênfase ao defeso do camarão sete-barbas (Xiphopenaeus kroyeri), analisando o papel das principais políticas públicas relacionadas a essa medida.

\section{METODOLOGIA}

A área de estudo contempla o entorno do município de Penha, localizado no litoral centro-norte de Santa Catarina (260 46' S e 48 38' W, Fig. 1), com área de 58.748 km², e população, em 2010, de pouco mais de 25 mil habitantes (INSTITUTO BRASILEIRO DE GEOGRAFIA E ESTATÍSTICA [IBGE], 2015), limitando-se ao Sul com Navegantes, ao Oeste e Norte, com Piçarras, e a Leste, com o oceano Atlântico. A economia do município está impulsionada pelo turismo, enquanto cresce a atividade de maricultura, mas a pesca artesanal nas três áreas indicadas na figura 1 é uma das principais atividades, tradicionalmente realizada no município, envolvendo um grande número de famílias, especialmente dependentes da pesca de arrasto de camarões e da pesca de emalhe (BRANCO, 2005).

Figura 1 - Localização da área de estudo, indicando as áreas de pesca do camarão sete-barbas (Xiphopenaeus kroyeri) pela frota artesanal, no município de Penha, SC

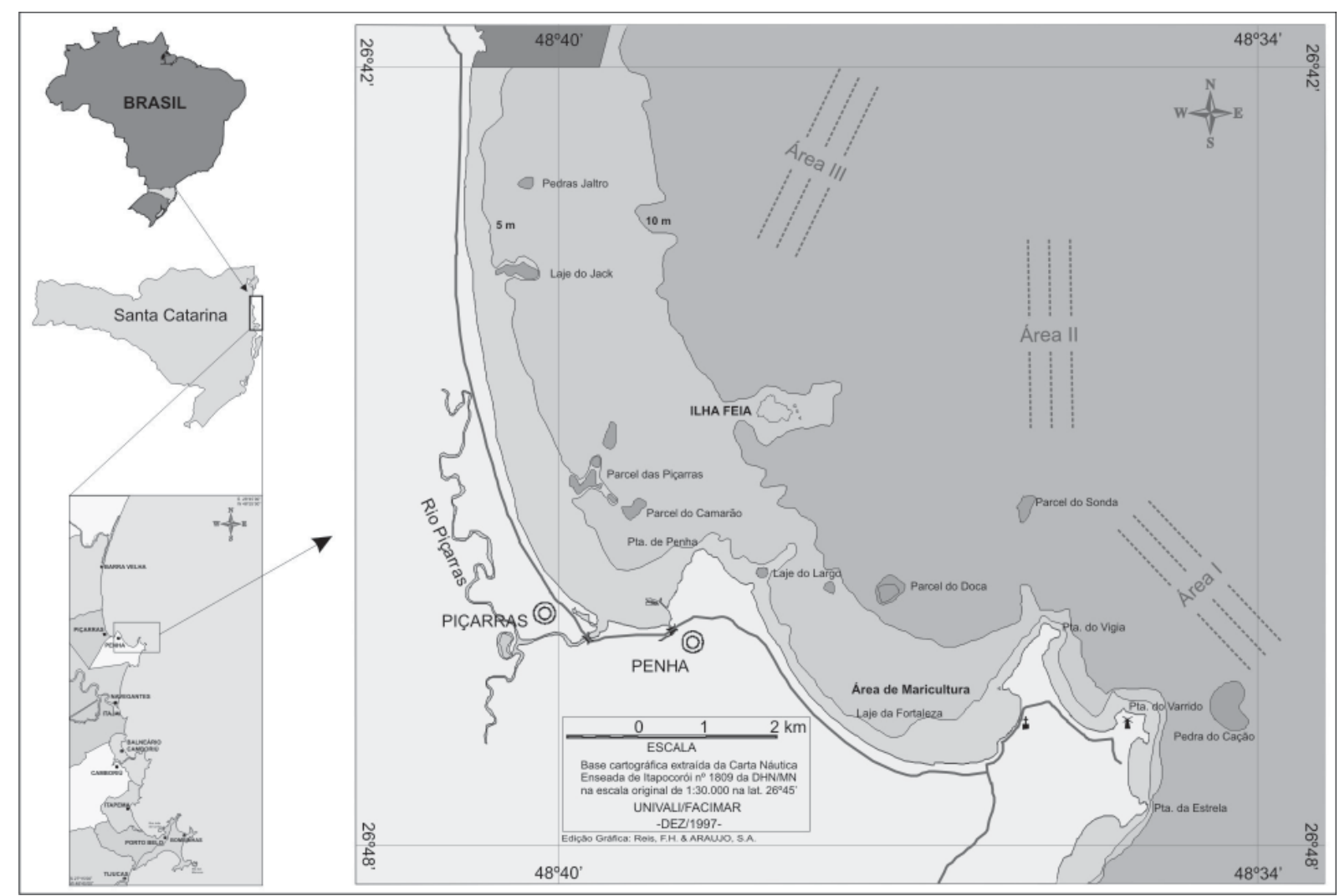

Fonte: Branco et al. (2013).

Para a realização da pesquisa, foram utilizados dados primários e secundários referentes à pesca artesanal do camarão sete-barbas no município. Os dados primários foram coletados por meio de entrevistas semiestruturadas, sendo utilizadas algumas respostas de um roteiro com 60 questões, nas quais o pesquisador coletou informações a partir de perguntas-chave 
sobre a atividade pesqueira, incluindo aspectos legais, institucionais e socioeconômicos. Foram entrevistados aleatoriamente 45 pescadores artesanais, abordando-os em seu local de trabaIho. Antes da realização de cada entrevista, o pescador assinou um termo de consentimento livre esclarecido, em que concordou em conceder uma entrevista com finalidade de pesquisa acadêmica, estando preservado o anonimato dos participantes.

Para a definição do número de entrevistas, utilizou-se como base a média da contagem do número de embarcações atracadas na praia da Armação do Itapocoroy, realizada em três momentos diferentes no ano de 2016 (115 \pm 8 embarcações), e a média de 75 embarcações em atuação definida por Branco (2005) para o mesmo local. Os dados oficiais encontrados sobre o número de pescadores artesanais para o município de Penha diferem consideravelmente nas diferentes fontes (Associações locais, Colônia de Pesca, cadastro do Registro Geral da Pesca e do Seguro-Defeso), e não há informações específicas nos cadastros para a pesca do camarão sete-barbas.

Após coletados, os dados foram tabelados em planilhas eletrônicas, sendo determinadas as médias e desvios padrão e elaborados gráficos e tabelas. Os dados secundários foram obtidos juntos às entidades do setor (associação de pescadores, colônia de pesca), instituições que atuam na área (Universidade do Vale do Itajaí, Instituto Federal de Santa Catarina), e banco de dados oficiais (Portal da Transparência, IBGE).

Através de levantamento atualizado da legislação, foram identificadas as normas legais relacionadas à pesca artesanal, ao nível federal, estadual e municipal. Informações sobre os aspectos legais foram obtidas através das entrevistas e dados secundários, analisadas com base na legislação da atividade, identificando normas que regem e sua adequação às práticas adotadas no município, além de mapear dificuldades encontradas e os possíveis entraves existentes no setor (CUNHA; CALLOU, 2013; ELER; MILLANI, 2007).

\section{RESULTADOS E DISCUSSÃO}

\subsection{Aspectos legais da pesca artesanal do camarão sete-barbas}

As principais normas que regulamentam a pesca artesanal do camarão em Penha, nos níveis federal, estadual e municipal são sumarizadas, respectivamente nas tabelas 1, 2 e 3 . Foram identificadas 36 normas, que, direta ou indiretamente, regulamentam a atividade, sendo 27 diretamente relacionadas à pesca, como registro da atividade, períodos de defeso, permissão para embarcações, seguro defeso e normas municipais na pesca artesanal.

Das normas levantadas, 30 foram instituídas por órgãos federais, quatro por municipais e duas por estaduais. Números semelhantes foram registrados no litoral do Paraná, com 30 instrumentos normativos vigentes em 2009 para a pesca profissional (26 federais e quatro estaduais) (CALDEIRA; MAFRA; MALHEIROS, 2016). 
Tabela 1 - Normas relacionadas à pesca artesanal do camarão em Penha, SC, em ordem cronológica crescente, emitidas por órgãos federais

\begin{tabular}{|c|c|}
\hline \multicolumn{2}{|c|}{ NORMAS EMITIDAS POR ÓRGÃOS FEDERAIS } \\
\hline LEGISLAÇÃO & ASSUNTO \\
\hline Decreto-Lei n. 221, (28/02/1967) & Proteção e estímulos à pesca. \\
\hline Portaria SUDEPE n. 55 (20/12/1984) & $\begin{array}{l}\text { Tamanho mínimo para pesca do camarão (Sudeste e } \\
\text { Sul). }\end{array}$ \\
\hline Portaria SUDEPE n. 56 (20/12/1984) & Permissão da pesca de Camarão com redes de arrasto \\
\hline Lei n. 9.433 (08/01/1997) & Política Nacional de Recursos Hídricos \\
\hline Portaria IBAMA n. 97 (22/08/1997) & $\begin{array}{l}\text { Regulamenta a pesca do camarão (entre os paralelos } \\
18^{\circ} 20^{\prime} \mathrm{S} \text { e } 28^{\circ} 40^{\prime} \mathrm{S} \text { ) }\end{array}$ \\
\hline Lei n. 9.537 (11/12/1997) & Segurança do tráfego aquaviário (LESTA/ RLESTA) \\
\hline Lei n. 9.605 (12/02/1998) & Lei de crimes ambientais \\
\hline Lei $n .10 .779(25 / 11 / 2003)$ & Seguro desemprego ao pescador artesanal \\
\hline $\begin{array}{l}\text { Norma da Autoridade Marítima NORMAM } \\
\text { 13/DPC (2003) }\end{array}$ & Carreira dos aquaviários (3o grupo: Pescadores) \\
\hline Instrução Normativa n. 03 (12/05/2004) & $\begin{array}{l}\text { Registro Geral da Pesca. (Alterada pela IN SEAP n. } \\
\text { 12/2006; IN MPA n. 06/2011; IN MPA n. 08/2012) }\end{array}$ \\
\hline $\begin{array}{l}\text { Res. CONAMA n. } 357 \text { (17/03/2005). Alterada } \\
\text { (Resolução 410/2009 e 430/2011) }\end{array}$ & $\begin{array}{l}\text { Classificação dos corpos de água (Classe de água para } \\
\text { desenvolvimento da Pesca) }\end{array}$ \\
\hline Instrução Normativa n. 09 (29/06/2005) & Preços Públicos dos Serviços do MPA \\
\hline $\begin{array}{l}\text { Norma da Autoridade Marítima } \\
\text { NORMAM2/DPC (2005) }\end{array}$ & Normas para navegação interior \\
\hline Portaria MMA n. 43 (07/02/2006) & Revoga o período de defeso do Camarão \\
\hline $\begin{array}{l}\text { Instrução Normativa IBAMA n. } 164 \\
(17 / 07 / 2007)\end{array}$ & Limita a frota de arrasto de captura do camarão \\
\hline $\begin{array}{l}\text { Instrução Normativa SEAP/PR n. } 18 \\
(27 / 07 / 2007)\end{array}$ & $\begin{array}{l}\text { Permissão de pesca para operar na captura do } \\
\text { camarão }\end{array}$ \\
\hline $\begin{array}{l}\text { Instrução Normativa IBAMA n. } 189 \\
\text { (23/09/2008) }\end{array}$ & Defeso do camarão \\
\hline LEI n. 11.959 (29/06/2009) & Política Nacional da Aquicultura e da Pesca \\
\hline $\begin{array}{l}\text { Instrução Normativa MMA n. } 31 \\
\text { (03/12/2009) }\end{array}$ & Cadastro Técnico Federal \\
\hline $\begin{array}{l}\text { Instrução Normativa Interministerial MMA } \\
\text { SEAP/PR n. } 05 \text { (13/04/2010) }\end{array}$ & $\begin{array}{l}\text { Dispensa dos "Mapas de Bordo", a frota de pesca de } \\
\text { camarão }\end{array}$ \\
\hline Instrução Normativa MPA n. 7 (19/05/2010) & $\begin{array}{l}\text { Programa de Revitalização da Frota Pesqueira } \\
\text { Artesanal - REVITALIZA }\end{array}$ \\
\hline Instrução Normativa n. 06 (29/06/2012) & $\begin{array}{l}\text { Registro Geral da Atividade Pesqueira (Pescador } \\
\text { Profissional) }\end{array}$ \\
\hline Portaria n. 39 (23/07/2012) & Licença de Pescador Profissional \\
\hline Portaria MPS n. 79 (12/03/2014) & $\begin{array}{l}\text { Embarcações miúdas utilizadas na pesca (para seguro } \\
\text { defeso) }\end{array}$ \\
\hline Decreto n. 8.425 (31/03/2015) & $\begin{array}{l}\text { Registro Geral da Atividade Pesqueira (autorização, } \\
\text { permissão ou licença) }\end{array}$ \\
\hline Decreto n. 8.424 (31/03/2015) & Seguro-desemprego (pescador profissional artesanal) \\
\hline Lei $n .13 .134$ (16/06/2015) & Programa do Seguro-Desemprego e Abono Salarial \\
\hline $\begin{array}{l}\text { Instrução Normativa PRES/INSS n. } 83 \\
(18 / 12 / 2015)\end{array}$ & $\begin{array}{l}\text { Seguro Desemprego (procedimentos para pescador } \\
\text { artesanal) }\end{array}$ \\
\hline $\begin{array}{l}\text { Resolução MTPS/CODEFAT n. } 759 \\
\text { (09/03/2016) }\end{array}$ & $\begin{array}{l}\text { Critérios de pagamento do benefício Seguro- } \\
\text { Desemprego (pescador artesanal) }\end{array}$ \\
\hline Portaria MTPS n. 600 (10/05/2016) & Seguro-Desemprego (pescador artesanal) \\
\hline
\end{tabular}

Fonte: Elaborada pelos autores. 
Tratando-se de normas emitidas por órgãos estaduais, não foi encontrado nenhum ato normativo específico da pesca artesanal; há uma resolução e uma instrução normativa que tratam das atividades que necessitam de autorização do órgão ambiental (Tabela 2), dentre elas, a preparação ou beneficiamento do pescado no município de Penha. Dos pescadores entrevistados, 79,17\% afirmam fazer algum tipo de preparação do seu pescado para venda, enquadrando-se nas normativas citadas e sujeitos ao licenciamento ou cadastro ambiental, de acordo com o tamanho da área utilizada.

Tabela 2 - Relação das normas de pesca artesanal do camarão em Penha, SC, em ordem cronológica crescente, emitidas por órgãos estaduais

\begin{tabular}{lc}
\hline \multicolumn{1}{c}{ LEGISLAÇÃO } & $\begin{array}{c}\text { NORMAS EMITIDAS POR ÓRGÃOS ESTADUAIS } \\
\text { ASSUNTO/TEXTO RELACIONADO À PESCA }\end{array}$ \\
\hline RES. CONSEMA n. 13/2012 & $\begin{array}{l}\text { Listagem das Atividades Consideradas Potencialmente Causadoras } \\
\text { de Degradação Ambiental } \\
\text { IN FATMA n. 34/2015 }\end{array}$ \\
$\begin{array}{l}\text { Atividades sujeitas ao cadastro ambiental. (Preparação ou } \\
\text { beneficiamento de pescado) }\end{array}$ \\
\hline
\end{tabular}

Fonte: Elaborada pelos autores.

Em Penha, foram localizados quatro atos normativos que tratam da pesca artesanal (Tabela 3), incluindo, na lei orgânica do município, a previsão para elaboração do plano de desenvolvimento agrícola e pesqueiro, que não foi localizado. Essas normas sugerem que a pesca artesanal é uma atividade tradicional na região, de importância econômica e social, porém normatizada basicamente por órgãos federais.

Tabela 3 - Relação das normas de pesca artesanal do camarão em Penha, SC, em ordem cronológica crescente, emitidas por órgãos municipais

\begin{tabular}{|c|c|}
\hline \multicolumn{2}{|r|}{ NORMAS EMITIDAS POR ÓRGÃOS MUNICIPAIS } \\
\hline LEGISLAÇÃO & ASSUNTO/TEXTO RELACIONADO À PESCA \\
\hline $\begin{array}{l}\text { Lei Orgânica do Município } \\
\text { de Penha } \text { n. } 1071 \text { de }\end{array}$ & $\begin{array}{l}\text { Trata da autonomia política, legislativa, administrativa e financeira do } \\
\text { Município de Penha. }\end{array}$ \\
\hline & $\begin{array}{l}\text { "Fica proibido no mar que banha o litoral do Município a pesca } \\
\text { submarina, reservada a atividade dessa natureza exercida pelos } \\
\text { pescadoresartesanais, devidamente inscritos na Colônia de Pescadores, } \\
\text { desde que sem a utilização de explosivos ou armas de propulsão". }\end{array}$ \\
\hline & $\begin{array}{l}\text { "O Município de Penha promoverá política de desenvolvimento } \\
\text { agrícola e pesqueiro, de acordo com as aptidões econômicas sociais } \\
\text { e dos recursos naturais, mediante a elaboração de um plano de } \\
\text { desenvolvimento agrícola e pesqueiro". }\end{array}$ \\
\hline Lei Complementar $n$ & Institui o Código Urbanístico do Município de Penha. \\
\hline $\begin{array}{l}\text { de } 14 \text { de setembro de } \\
2007 .\end{array}$ & $\begin{array}{l}\text { "A Estratégia de Qualificação do patrimônio socioambiental de Penha } \\
\text { deverá ser desenvolvida pelos órgãos municipais competentes em } \\
\text { parceria com a comunidade, visando promover a implantação de } \\
\text { espaços e equipamentos voltados à valorização e ao fortalecimento } \\
\text { de atividades produtivas tradicionais, como os produtores rurais e } \\
\text { pescadores artesanais". }\end{array}$ \\
\hline
\end{tabular}




\begin{tabular}{|c|c|}
\hline \multicolumn{2}{|r|}{ NORMAS EMITIDAS POR ÓRGÃOS MUNICIPAIS } \\
\hline LEGISLACC̃̃O & ASSUNTO/TEXTO RELACIONADO À PESCA \\
\hline $\begin{array}{l}\text { Lei Municipal n. 2.214, de } \\
25 \text { de junho de } 2008 .\end{array}$ & $\begin{array}{l}\text { Proíbe a entrada de banhistas e terceiros nas embarcações dos } \\
\text { pescadores artesanais ancoradas nas praias do Município de Penha. }\end{array}$ \\
\hline $\begin{array}{l}\text { Decreto n. } 158 \text {, de } 08 \text { de } \\
\text { dezembro de } 2006 \text {. }\end{array}$ & $\begin{array}{l}\text { Declara de utilidade pública para fins de desapropriação amigável ou } \\
\text { judicial, aforamento e a ocupação, bem como benfeitorias existentes } \\
\text { sobre terreno de marinha para implantação de Parque Municipal de } \\
\text { Proteção Ambiental. }\end{array}$ \\
\hline
\end{tabular}

Fonte: Elaborada pelos autores.

O emaranhado de regras que envolvem o setor pesqueiro no município de Penha inclui também diversos atores; além dos pescadores artesanais, os trabalhadores do beneficiamento do pescado (mulheres em sua maioria), as indústrias formais e informais de beneficiamento, os atravessadores de pescado e as instituições locais, constituem o cenário da pesca no município. O pouco entendimento sobre o funcionamento de todas essas relações resulta em conflitos legais e institucionais, com consequências sociais, econômicas e ambientais que não contribuem para o desenvolvimento da atividade.

As normas vigentes na pesca artesanal, em sua maioria, foram elaboradas por órgãos federais (Tabela 1), sem a participação direta do setor envolvido, retratando o modelo de pirâmide descrito por Jentoft (2007), focado na execução e controle do setor pesqueiro. Das normas encontradas para o exercício da pesca do camarão em Penha, 27 foram estabelecidas nos últimos 15 anos (72,97\%), quando 81,82\% dos entrevistados estavam em atividade, mas apenas 33,33\% têm conhecimento do Registro Geral da Atividade Pesqueira (RGP), e 93,75\% possuem a "carteira da pesca/SEAP" ou "carteira da colônia". Pelo Decreto-Lei n. 221 de 1967, esse documento é obrigatório na atividade pesqueira, ratificado pela Lei n. 11.959/2009 e regulamentado no Decreto n. 8.425/2015.

Outro exemplo é a instituição do período de defeso para o camarão sete-barbas; há, entre os entrevistados, consenso de que essa medida não está na data correta, embora a norma que regulamenta o defeso (IN 189/2008) indique serem apoiadas pelas reuniões participativas da comunidade de pescadores em discussões que refletiriam o anseio dos usuários desse recurso. A pouca representatividade dos órgãos locais (colônia de pesca da Penha), relatada durante as entrevistas, explicaria a "participação dos pescadores artesanais", visto que parece não representar a comunidade pesqueira local.

As inúmeras mudanças, ou até mesmo a falta de um único órgão de referência para a pesca no Brasil, podem contribuir para a desinformação e falta de participação por parte dos pescadores. Utilizando-se o exemplo do RGP, quando instituído, era de competência da Superintendência do Desenvolvimento da Pesca (SUDEPE), extinta em 1989, passando para o Instituto Brasileiro do Meio Ambiente e dos Recursos Naturais Renováveis (IBAMA) até a década de 90, daí ao Ministério da Agricultura, Pecuária e Abastecimento (MAPA).

Em 2003, o RGP era de competência da Secretaria Especial de Aquicultura e Pesca da Presidência da República, transformada pela Lei n. 11.958/2009 em Ministério da Pesca e Aquicultura (MPA), que foi extinto em 2015, voltando o RGP à competência do MAPA (Secretaria de Aquicultura e Pesca). Entretanto, para o exercício da pesca artesanal embarcada, outros documentos são necessários envolvendo o IBAMA (Cadastro Técnico Federal [CTF]), Marinha do Brasil 
(Caderneta de Inscrição e Registro [CIR] e da documentação da embarcação), e as instituições locais (Colônia de Pesca, Associação de Pescadores- RGP).

Esse contexto ressalta a ausência de um órgão ou instituição de referência local, obrigando ao pescador se reportar a diferentes instituições, onde $60,71 \%$ dos entrevistados não sabem a quem procurar no município, mesmo que 90,91\% estejam há mais de 10 anos atuando na pesca. A diversidade de práticas pesqueiras e as limitações do processo de gestão resultam num quadro normativo complexo e pouco difundido entre os pescadores (CALDEIRA; MAFRA; MALHEIROS, 2016).

O cenário de desinformação configura-se no reflexo atual do modelo de gestão hierárquico, no qual o estado está no ápice (JENTOFT, 2007), a autoridade e a responsabilidade são centralizados, num mecanismo de cima para baixo, com ênfase na execução e no controle dos usuários, inexistindo diálogo entre as normas estabelecidas e os usuários dos recursos. As consequências podem ser evidenciadas pela ausência ou descrença de representatividade, apesar da legislação da pesca. Também há uma deficiência de informação entre os pescadores no país, o que perpassa por gerações e impede de buscar melhores condições de sobrevivência (PEDÓ; SANTOS, 2015).

\subsection{O defeso e a pesca artesanal em Penha}

Entre as medidas de ordenamento e gestão da pesca no Brasil, o defeso para a pesca artesanal do camarão tem gerado inúmeras discussões no setor pesqueiro. A Instrução Normativa (IN) IBAMA n. 189, de 23 de setembro de 2008, estabelece o defeso para os camarões rosa (Farfantepenaeus paulensis, F. brasiliensis e F. subtilis), sete-barbas (Xiphopenaeus kroyeri), branco (Litopenaeus schmitti), Santana ou vermelho (Pleoticus muelleri) e camarão barba ruça (Artemesia longinaris). Essa IN proíbe a pesca marinha entre a divisa dos estados do Espírito Santo e Rio de Janeiro e a Foz do Arroio Chuí, RS, de 1ำ de março a 31 de maio.

Entre os pescadores artesanais entrevistados na região de Penha, 91,67\% afirmam conhecer o período de defeso, e 61,90\% acreditam que a mudança na data e fiscalização no período de defeso seriam as melhores alternativas para a manutenção do recurso, visto que, para 69,57\% dos pescadores, o melhor período de pesca do camarão sete-barbas seria durante o defeso. Essa tendência também foi registrada por Bail e Branco (2007) no mesmo local de estudo, onde $85,5 \%$ dos entrevistados obtiveram as maiores capturas nos meses do defeso, sendo que $96,4 \%$ tinham conhecimento do fechamento da pesca nesse período.

Trabalhos como o de Branco et al. (2013) em Penha, SC, evidenciam uma diferença entre os períodos de recrutamento encontrados (maio, julho e novembro, sendo o último mais acentuado), e o período de defeso (março, abril e maio), o que causa preocupação acerca da manutenção dos estoques locais. Ainda, os resultados obtidos por Branco (2005) demonstram que as maiores taxas de captura de camarão sete-barbas sempre ocorreram entre dezembro e maio na Armação do Itapocoroy (Penha, SC), com picos anuais alterando-se entre março e abril (meses do defeso). Os trabalhos científicos corroboram, nesse sentido, o conhecimento dos pescadores locais; de acordo com Branco et al. (2013), a pesca do camarão sete-barbas deveria ser evitada no mês de novembro, principalmente nos locais mais rasos, para preservar o desenvolvimento dos juvenis e manter a continuidade dessa importante modalidade de pesca no litoral brasileiro. 
Grabowski (2012), em estudo sobre o camarão sete-barbas realizado no litoral norte de Santa Catarina, afirma que o maior número de indivíduos coletados foi observado no mês de maio, sendo o outono a estação do ano em que o maior número de camarões foi coletado.

Pode-se perceber, dessa forma, que, seja por ineficiência da fiscalização, seja por inadequação das normas, o período de defeso do camarão sete-barbas na comunidade em questão não está sendo efetivo, prevalecendo o conhecimento tradicional dos pescadores às normas legais vigentes. Rebouças, Filardi e Vieira (2006) afirmam que muitas comunidades desenvolveram regras informais de conduta no que diz respeito às modalidades possíveis de acesso e uso dos recursos pesqueiros; de acordo com os autores, grande parte dessas regras baseia-se no conhecimento ecológico tradicional dos pescadores e mostraram-se capazes de diminuir os conflitos. Jentoft et al. (2009) destacam também que pescadores e gestores costeiros geralmente assumem que, na ausência de interferência do Estado, não existe nenhuma regulação e, consequentemente, o caos pode ser inevitável, e então as comunidades e os grupos de usuários muitas vezes iniciam suas próprias maneiras de regular a atividade.

Nesse sentido, o período de defeso poderia ser realinhado conforme o conhecimento dos pescadores e pesquisas científicas realizados na região, lançando-se mão da gestão com base participativa, buscando-se adequar à realidade local. Essa escolha configurar-se-ia na perspectiva do chamado pluralismo jurídico, quando se assume que o Estado não é o único legislador, que a lei não é exclusiva das sociedades estatais, mas que pode existir uma lei popular ou tradicional, na ausência ou em adição à norma estatal (JENTOFT et al., 2009). A lei, nesse caso, é entendida como um conceito mais abrangente e, na perspectiva da gestão participativa, deve estimular a reconciliação das regras inconsistentes e dos princípios conflitantes na comunidade, em que os usuários podem desenvolver seus próprios sistemas legais para evitar consequências negativas (VON BENDA-BECKMANN; VON BENDA-BECKMANN, 2006; JENTOFT et al., 2009).

\subsection{A questão do seguro-defeso}

A instituição dos períodos de defeso levou também à criação de alternativas de renda para os pescadores, com o objetivo principal de evitar a pesca naquele período e contribuir para a sustentabilidade da atividade. Para isso, foi instituído no Brasil o seguro-defeso, para conceder um auxílio ao pescador profissional artesanal durante o período em que a pesca não é permitida (Lei n. 10.779/2003; Decreto n. 8.424/2015; Instrução Normativa n. 83/2015 PRES/INSS). De acordo com Campos e Chaves (2014), o programa seguro defeso surgiu no início dos anos 1990, na esteira dos avanços da Constituição Federal de 1988, como uma extensão do programa seguro-desemprego, específico para o pescador artesanal, focado na preservação de várias espécies do ecossistema brasileiro.

Para receber o auxílio previsto pelo seguro-defeso, o pescador artesanal precisa comprovar sua condição de segurado especial para essa categoria, incluindo a constatação de sua atividade profissional ininterruptamente, de forma artesanal, individualmente ou em regime de economia familiar, durante o período de defeso da atividade pesqueira. Essa comprovação, no entanto, tem gerado inúmeras controvérsias no Brasil, e observa-se um cenário de descaso e ilegalidade para a atividade pesqueira artesanal, o que pode ser observado pela ausência de dados concisos e políticas de estado para a pesca artesanal, e por Souza, Lobato e Camargo (2007) e Capellesso e Cazella (2011), além dos dados apontados neste estudo para o município de Penha. 
A concessão do seguro-defeso no Brasil representou um investimento de $\mathrm{R} \$$ 10.279.818.033,28 entre os anos de 2011 e 2016, de acordo com dados do Portal de Transparência do Governo Federal, sendo R\$259.301.223,94 para o estado de Santa Catarina. Somente no município de Penha foram pagos mais de sete milhões de reais $(\mathrm{R} \$ 7.572 .841,96)$ em indenizações referentes ao seguro defeso para pescadores artesanais.

Branco (2005) estimou a produção de camarão em 130,82 toneladas ao ano no município de Penha; utilizando os valores médios de venda do camarão encontrados nessa pesquisa $(R \$ 5,23)$, e considerando que as capturas de camarões no mundo tem se mantido estáveis desde 2012 (FAO, 2016), calcula-se que a pesca do camarão gera em torno de $\mathrm{R} \$ 680.000,00$ ao ano no município. Comparados aos dados de indenizações, e considerando que a pesca do camarão é a mais praticada no município, os recursos destinados ao pagamento de seguro-defeso foram 1,86 vezes maiores que a produção pesqueira anual de camarão estimada para o município.

Alguns dados encontrados também são controversos (Tabela 4); constam no cadastro de segurados disponível no Portal da Transparência do Governo federal, nos anos de 2011 a 2016, 885 pescadores artesanais nesse município, sendo a sua maioria mulheres (68,7\%). Dados do Ministério da Agricultura apontam 718 pescadores que tiveram o RGP - categoria Pescador, deferidos em 2016 na cidade de Penha. Estão cadastrados na Associação Beneficente de Pescadores Artesanais do Município de Penha 333 pescadores, sendo 257 mulheres (77,18\%), constando nos registros da associação 42 embarcações de pesca no município. A maioria desses associados são trabalhadores do beneficiamento ou preparação de pescados, não estando enquadrados na categoria de pescador profissional artesanal, de acordo com a legislação.

Na pesquisa de campo realizada no ano de 2016, não foi constatada a presença de nenhuma mulher entre os pescadores artesanais embarcados, sendo que apenas dois pescadores relataram receber auxílio da esposa durante a atividade de pesca no mar (4,44\%, tabela 4). Os dados disponíveis apontam uma diferença de até sete vezes no número de pescadores no município, entre aqueles que recebem o seguro defeso e os números observados em campo.

Tabela 4 - Número de pescadores do município de Penha, de acordo com cadastros oficiais, levantados pela pesquisa em diferentes fontes, e observados em campo

\begin{tabular}{lccc}
\hline \multicolumn{1}{c}{ Fonte } & Número de pescadores & Homens (\%) & Mulheres (\%) \\
\hline Portal da Transparência & 885 & 31,30 & 68,79 \\
Registro Geral da Pesca & 718 & - & - \\
Associação de Pescadores & 333 & 22,82 & 77,18 \\
$\begin{array}{l}\text { Contagem de embarcações em } \\
\text { campo (estimado pela pesquisa) }\end{array}$ & $128^{*}$ & 95,56 & 4,44 \\
\hline
\end{tabular}

*estimado, considerando 115 embarcações, nas quais 11\% da amostra declararam ter um ajudante a bordo) Fonte: Elaborada pelos autores.

Analisando as informações disponíveis, pode-se perceber que a maioria dos trabalhadores que recebem o seguro-defeso no município de Penha atuam no beneficiamento do pescado, e que não teriam direito a esse benefício. Muitos desses, mulheres em sua maioria (em torno de

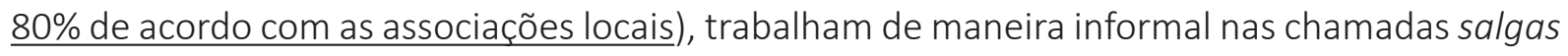
existentes no município, as quais caracterizam-se como indústrias ilegais de beneficiamento de pescado. Por não possuírem nenhum vínculo empregatício, essas mulheres ficam às margens 
das políticas públicas, e têm, no seguro-defeso, uma garantia de renda nos meses em que não há pescado para beneficiar. Muitas dessas trabalhadoras estão cadastradas como pescadoras artesanais, mas a função que exercem é distinta daquela para qual o seguro defeso foi criado, pois elas processam pescados de diferentes origens, incluindo empresas que terceirizam inadequadamente este serviço.

São evidências de que as políticas públicas precisam ser diferenciadas no Brasil, considerando que há um contingente de $40 \%$ de mulheres atuando na pesca no país, as quais muitas vezes ficam invisíveis aos olhos da sociedade (SILVA, 2014; ZHAO et al., 2013).

A necessidade de uma política específica aos trabalhadores de apoio à pesca vem de encontro ao estabelecido no Decreto n. 8.424/2015, o qual define que o seguro defeso será pago ao pescador profissional artesanal, e que o benefício não será extensível aos trabalhadores de apoio à pesca artesanal, nem aos componentes do grupo familiar do pescador profissional artesanal, conforme destaca o parágrafo 60 do Artigo 1은

$\S 60$ A concessão do benefício não será extensível aos trabalhadores de apoio à pesca artesanal, assim definidos em legislação específica, e nem aos componentes do grupo familiar do pescador profissional artesanal que não satisfaçam, individualmente, os requisitos e as condições estabelecidos neste Decreto. (BRASIL, 2015b).

Essa situação de ilegalidade para o seguro defeso não é exclusiva do município de Penha; Souza, Lobato e Camargo (2007) e Capellesso e Cazella (2011) também afirmam que os pescadores entrevistados em seus estudos apontam problemas de fraude no seguro defeso, visto que consideram alguns beneficiários como não-pescadores.

Fatos como esses demonstram a fragilidade das políticas públicas voltadas à pesca artesanal no Brasil e a ausência de dados e diagnósticos que retratem a realidade do setor quando da proposição de novas políticas ou ações do estado. Quando se analisa a base de dados pesqueira no Brasil, por exemplo, autores como Silva (2014) verificam uma notável fragilidade e descontinuidade, principalmente para a pesca artesanal. Gillett (2010) também aponta que, em muitos países, os principais fatores responsáveis pelo fracasso das ações de gestão estão relacionados à deficiência dos órgãos ligados à pesca, à falta de vontade política e à uma base jurídica inadequada.

Cabe considerar que, na prática, o papel mais importante do defeso para a comunidade em questão tem sido o recebimento do seguro-defeso, pois não há um entedimento de que essa política cumpra a função ecológica a qual se propõe. Durante a pesquisa, $43,48 \%$ dos pescadores admitiram que pescam na época de defeso, o que pôde ser observado durante as pesquisas em campo nesse período; ainda, um número expressivo $(35,48 \%)$ relatou não possuir licença para a prática da pesca que exerce.

Como autônomos, os pescadores artesanais estabeleceram uma relação de dependência com a atividade pesqueira, a qual se sobressai frente ao risco do trabalho de forma ilegal. Somado ao desconhecimento em relação aos aspectos legais e ecológicos, o papel dessas normas parece, na prática, muito distante do qual se propõe. Destaca-se um relato, no qual o entrevistado acredita que a melhor alternativa para não ter sua embarcação apreendida, é não possuir documento desta: "Meu barco não tem documento, e também não tenho licença de pesca [...] porque, se eu tiver documento, eles podem apreender se eu pescar na parada; $e$, se eu não tenho, eles não têm como prender". Ainda um outro relato que destaca a falta de entendimento e a dependência em relação à pesca: "Eu pesco no defeso, mas é porque eu não tenho a carteirinha, eu não recebo o seguro na parada, então eu posso pescar... eu tenho que pescar." 
Conforme destaca Von Benda-Beckmann e Von Benda-Beckmann (2006), é necessário considerar o que as pessoas fazem, na medida em que elas são influenciadas por uma orientação em um determinado tipo de norma, bem como as consequências disso. Na proposição de uma norma fica evidente a necessidade de se considerar o contexto no qual os atores estão inseridos. Readequar algumas normas, na perspectiva de uma gestão de base participativa, mostra-se prioritário para a um novo caminho na gestão da pesca artesanal.

\section{CONSIDERAÇÕES FINAIS}

Constatou-se na pesquisa a existência de inúmeros atos normativos que regulamentam a pesca artesanal do camarão sete-barbas, para o município de Penha, sendo a maioria estabelecida por órgãos federais. Muitas dessas normas, no entanto, parecem não estar sendo efetivas, havendo falta de conhecimento entre os pescadores das principais normas legais da atividade. Observou-se um grande número de embarcações exercendo a pesca de arrasto durante o período de defeso; no relato dos pescadores, um número expressivo afirmou não possuir licença de pesca ou documento da embarcação.

Pode-se verificar que não há um órgão representativo dos pescadores artesanais no município, fazendo com que as normas estabelecidas não contemplem o conhecimento tradicional e a participação dos pescadores. O resultado verifica-se no comportamento baseado nas escolhas desses usuários, especialmente frente à ausência do Estado.

De acordo com os dados pesquisados, há uma discrepância entre o número de beneficiários do seguro-defeso e de pescadores artesanais para o município, o que reflete a ausência de dados padronizados para a pesca artesanal e dificulta as estratégias de gestão. Nesse sentido, são necessárias ações que permitam redefinir o papel do defeso nessa comunidade, contemplando a participação dos usuários e da comunidade.

\section{REFERÊNCIAS}

BAIL, G. C.; BRANCO, J. O. Pesca artesanal do camarão sete-barbas: uma caracterização sócio-econômica na Penha, SC. Brazilian Journal of Aquatic Science and Technology, Itajaí, v. 11, n. 2, p. 25-32, 2007.

BRANCO, J. O. Biologia e pesca do camarão sete-barbas Xiphopenaeus kroyeri (Heller) (Crustacea, Penaeidae), na Armação do Itapocoroy, Penha, Santa Catarina, Brasil. Revista Brasileira de Zoologia, Curitiba, PR, v. 22, n. 4, p. 1050-62, 2005.

BRANCO, J. O. et al. Distribuição espaço-temporal das capturas do camarão sete-barbas na Armação do Itapocoroy, Penha, SC. Boletim do Instituto de Pesca, São Paulo, v. 39, n. 3, p. 237-50, 2013.

BRASIL. Ministério da Pesca e Aquicultura. Mapa da Pesca e da Aquicultura no Brasil. 2015a. Disponível em: <http://www.brasil.gov.br/economia-e-emprego/2015/03/ministerio-da-pesca-quer-quadruplicarproducao-aquicola-no-brasil>. Acesso em: 20 fev. 2017.

Decreto n. 8.424, de 31 de março de 2015. Regulamenta a Lei n. 10.779, de 25 de novembro de 2003, para dispor sobre a concessão do benefício de seguro-desemprego, durante o período de defeso, ao pescador profissional artesanal que exerce sua atividade exclusiva e ininterruptamente. 2015b. Disponível em: <http://www.planalto.gov.br/ccivil_03/_ato2015-2018/2015/decreto/D8424.htm>.

Ministério da Pesca e Aquicultura. Boletim Estatístico da Pesca e Aquicultura 2011. Brasília: Ministério da Pesca e Aquicultura, 2011.

CALDEIRA, G. A.; MAFRA, T. V.; MALHEIROS, H. Z. Limites e possibilidades para a gestão participativa da pesca no litoral do Paraná, sul do Brasil: experiências do Projeto "Nas Malhas da Inclusão". Desenvolvimento e Meio Ambiente, Curitiba, PR, v. 36, p. 331-53, abr. 2016. 
CAPELLESSO, A. J.; CAZELLA, A. A. Pesca artesanal entre crise econômica e problemas socioambientais: estudo de caso nos municípios de Garopaba e Imbituba (SC). Ambiente \& Sociedade, São Paulo, v. 14, n. 2, p. 15-33, jul./dez. 2011.

CUNHA, E. J.; CALLOU, A. B. F. Políticas públicas e capital social para o desenvolvimento local da pesca e da aquicultura no Vale do Piancó, Paraíba. Interações, Campo Grande, MS, v. 14, n. 2, p. 237-50, jul./dez. 2013.

DIEGUES, A. C. S. O mito moderno da natureza intocada. 3. ed. São Paulo: NUPAUB, 2001. 161p.

ELER, M. N.; MILLANI, T. J. Métodos de estudos de sustentabilidade aplicados a aquicultura. Revista Brasileira de Zootecnia, Viçosa, MG, v. 36, suplemento especial, p. 33-44, 2007.

FOOD AND AGRICULTURE ORGANIZATION OF THE UNITED NATIONS (FAO). The State of World Fisheries and Aquaculture 2016. Contributing to food security and nutrition for all. Rome: FAO. 2016. 200p.

. FAO no Brasil. Memória de Cooperação Técnica. 2013. Disponível em: <https://www.fao.org.br/ download/LivroFAOBrasilMemoriaCooperacaoTecnica.pdf>.

FRANCO, A. C. N. P. et al. Levantamento, sistematização e análise da legislação aplicada ao defeso da pesca de camarões para as regiões sudeste e sul do Brasil. Boletim do Instituto de Pesca, São Paulo, v. 35, n. 4, p. 687-99, 2009.

GILLETT, R. Marine fishery resources of the Pacific Islands. Rome: Food and Agriculture Organization of the United Nations (FAO), 2010. 2008. Global study of shrimp fisheries. Rome: Food and Agriculture Organization of the United Nations,

GRABOWSKI, R. C. Dinâmica populacional do camarão sete-barbas Xiphopenaeus kroyeri (Heller, 1862) (Crustacea: Decapoda) na Baía da Batitonga, Estado de Santa Catarina. 2012. Dissertação (Mestrado em Ciências Biológicas)- Universidade Estadual Paulista "Julio de Mesquita Filho" (UNESP), Botucatu, SP, 2012.

INSTITUTO BRASILEIRO DE GEOGRAFIA E ESTATístICA (IBGE). Perfil dos Municípios Brasileiros 2014. Rio de Janeiro: IBGE, 2015.

JENTOFT, S. et al. Fisheries co-management and legal pluralism: how an analytical problem becomes an institution alone. Human Organization, v. 68, n. 1, p. 27-38, 2009.

JENTOFT, S. Limits of governability: Institutional implications for fisheries and coastal governance. Marine Policy, v. 31, n. 4, p. 360-70, jul. 2007.

MÜLLER, F.; BURKHARD, B. The indicator side of ecosystem services. Ecosystem Services, v. 1, n. 1, p. 26-30, 2012.

PEDÓ, J. C. J.; SANTOS, U. A. F. Concessão do seguro defeso: uma influência na vida do pescador. Caderno de Graduação-Ciências Humanas e Sociais-UNIT, Aracaju, SE, v. 2, n. 3, p. 183-94, 2015.

PORTAL DA TRANSPARÊNCIA. Governo Federal. Pescador artesanal por estado/município. Disponível em: <http://www.portaltransparencia.gov.br/defeso/defesoListaEstados.asp>. Acesso em: 20 dez. 2016.

REBOUÇAS, G. N.; FILARDI, A. C. L.; VIEIRA, P. F. Gestão integrada e participativa da pesca artesanal: potencialidades e obstáculos no litoral do Estado de Santa Catarina. Ambiente \& Sociedade, São Paulo, v. 9, n. 2, p. 83-104, jul./dez. 2006.

SANTOS, M. C. F.; BRANCO, J. O.; BARBIERI, E. Biologia e pesca do camarão sete-barbas nos estados nordestinos brasileiros onde não há regulamentação do período de defeso. Boletim do Instituto de Pesca, São Paulo, v. 39, n. 3, p. 217-35, 2013.

SILVA, A. P. Pesca artesanal brasileira. Aspectos conceituais, históricos, institucionais e prospectivos. Palmas, TO: Embrapa Pesca e Aquicultura, 2014.

SOUZA, A. S. de.; LOBATO, A. B.; CAMARGO, S. A. F. de. Usos e costumes na comercialização de pescado no município de Manaus (AM): aspectos do meio ambiente do trabalho no porto e na feira da Panair. In: CONGRESSO NACIONAL DO CONPEDI, 12., 2007, Belo Horizonte, MG. Anais... Belo Horizonte: COMPEDI, 2007. 
UNIVERSIDADE DO VALE DO ITAJAÍ (UNIVALI). Boletim Estatístico da Pesca Industrial de Santa Catarina, Itajaí, SC, v. 13, n. 1, 2013.

VASCONCELLOS, M.; DIEGUES, A. C.; SALES, R. R. de. Limites e possibilidades na gestão da pesca artesanal costeira. In: Costa, A. (Org.). Nas redes da pesca artesanal. Brasília: IBAMA/PNUD, 2007, p. 15-84. v. 1.

VASQUES, R. O.; COUTO, E. C. G. Percepção dos pescadores quanto ao estabelecimento do período de defeso da pesca de arrasto para a região de Ilhéus (Bahia, Brasil). Revista de Gestão Costeira Integrada, v. 11, n. 4, p. 479-85, 2011.

VIANNA, L. F. de N.; BONETTI, J.; POLETTE, M. Gestão costeira integrada: análise da compatibilidade entre os instrumentos de uma política pública para o desenvolvimento da maricultura e um plano de gerenciamento costeiro no Brasil. Revista de Gestão Costeira Integrada, v. 12, n. 3, p. 357-72, 2012.

VON BENDA-BECKMANNN, F.; VON BENDA-BECKMANNN, K. The dynamics of change and continuity in plural legal orders. The Journal of Legal Pluralism and Unofficial Law, v. 38, n. 53-4, p. 1-44, 2006.

ZHAO, M. et al. Women as visible and invisible workers in fisheries: A case study of Northern England. Marine Policy, v. 37, p. 69-76, jan. 2013.

\section{Sobre os autores:}

Renata Costella Acauan: Mestrado em Ciência e Tecnologia Ambiental. Bacharel em Oceanografia. Docente da carreira de ensino básico, técnico e tecnológico do Instituto Federal de Santa Catarina, Departamento de Ensino, Pesquisa e Extensão, Área de Recursos Naturais. E-mail: renataacauan@gmail.com

Benjamim Teixeira: Mestrado e doutorado em Aquicultura pela Universidade Federal de Santa Catarina. Graduação em Oceanografia pela Universidade do Vale do Itajaí. Professor de nível técnico e tecnológico do Instituto Federal de Santa Catarina. E-mail: benjamim.teixeira@ifsc.edu.br

Marcus Polette: Pós-doutorado UPO-Sevilha, Espanha. Pós-doutorado em Ciências Políticas pela Universidade Federal de Santa Catarina. Doutorado e mestrado em Ecologia e Recursos Naturais, ambos pela Universidade Federal de São Carlos. Graduação em Geografia e em Oceanografia, ambas pela Fundação Universidade Federal do Rio Grande. Especialização em Gestão Costeira Integrada nas seguintes instituições: Universidade de Delft (Holanda), University of Rhode Island (EUA) e Universidade de Bologna (Itália). Pesquisador e professor da Universidade do Vale do Itajaí (UNIVALI). Colaborador no United Nations Pool of Experts- Regular Process (World Ocean Assessment [WOA]). Editor e fundador da Revista de Gestão Costeira Integrada para países de Língua Portuguesa. Professor da Universidade de La Republica- Uruguay no curso de Manejo Costero Integrado. E-mail: mpolette@univali.br

Joaquim Olinto Branco: Doutor e Pós-Doutor em Ecologia e Recursos Naturais pela Universidade Federal de São Carlos. Biólogo, Mestre e Doutor em Zoologia pela Universidade Federal do Paraná. Professor titular da Universidade do Vale do Itajaí. Coordenador do Grupo de Pesquisa do CNPq: Conservação dos Ecossistemas Costeiros. E-mail: branco@univali.br 